\title{
Pricing Strategies in Presence of Online Consumer Ratings - from the Product Customization Perspective
}

\author{
Tian $\mathrm{Li}^{1}$, Xueying Wang ${ }^{1}$, Yifan $\mathbf{W u}^{1}$ \\ ${ }^{1}$ East China University of Science and Technology, School of Business, Shanghai, China \\ litian@ecust.edu.cn,13127921070@163.com, yifanwu@ecust.edu.cn
}

Received 7 December 2018; received in revised form 8 October 2019; accepted 14 October 2019

\begin{abstract}
Although there is abundant evidence that online consumer ratings have significant impacts on firms' pricing strategies, it is unclear how such impacts are influenced by the degree of product customization. This paper sets up a two-period dynamic model to analyze a firm's pricing strategies and the changes in its profitability when it sells products with different customization degrees (i.e., niche, neutral or mainstream). Consumers are uninformed of the product value. However, the first-period consumers generate online consumer ratings after their consumptions, and such ratings enable the second-period consumers to better understand the product value and thus to improve their purchasing decisions. Our results show that, in anticipation of the impacts of online consumer reviews, the firm should adjust its pricing strategy according to the customization degree of its product. In particular, for neutral products, the firm should lower its expected price in the second period comparing to its first period price, but for niche and mainstream products, the pricing adjustments over periods depend on the product value.
\end{abstract}

Keywords: Pricing strategy, Product customization, Online consumer rating, Niche product, Neutral product, Mainstream product 


\section{Introduction}

The online shopping population is growing all over the world in recent years. According to the monitoring data of China E-Commerce Research Center (100EC.CN), the number of online shoppers in China has reached 516 million in the first half of 2017, while this number was 480 million in the first half of 2016, exhibiting an increase of $7.5 \%$. However, this growth is hindered by some factors, one of which is that consumers cannot accurately evaluate the value of the product due to spatial separation from online sellers. Online consumer ratings, generated by online buyers, can greatly help reduce consumers' uncertainties about the product value [7]. These online ratings are very important for new consumers, who have no experience with such product, to make purchasing decisions. While the highest ratings are a good predictor of rapidly growing future sales, the presence of poor ratings is not a good predictor of poor sales [44].

Due to their deep impacts on consumers' purchasing decisions, online consumer ratings affect many firms' pricing strategies. For example, different brands of mobile phones released in the same period show different price changes due to the different online rating levels of consumers. The firm cuts prices more quickly and drastically when its mobile phones have lower consumer ratings, while the firm cuts prices more slowly and slightly when its mobile phones have higher consumer ratings. Figure 1 shows the relevant data from Zhongguancun Online, a third-party platform where consumers can comment on a product and rate from1 to 10 (Site 1). All the websites cited in this paper are listed in the websites list section.

Products are categorized by their degrees of specialization or customization. Some products are designed to cater to a broad spectrum of tastes, which are called mainstream products. Some products are customized to meet the needs of specific people, which are called niche products [41]. Niche products have narrow appeal and more consumers have a long distance to the product (high product misfit), while mainstream products have broad appeal and more consumers have a short distance to the product (low product misfit). The products falling between niche and mainstream products are called neutral products. Panel data collected from the Amazon Web shows that positive reviews boost sales of mainstream products and negative reviews hurt sales of niche products more [17].

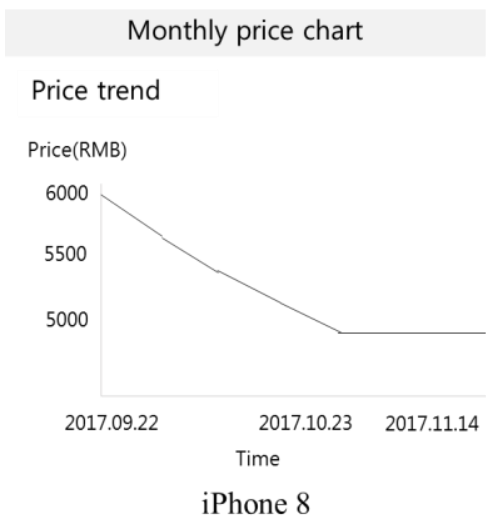

Average rating: 5.0

Time to market:2017/9/22

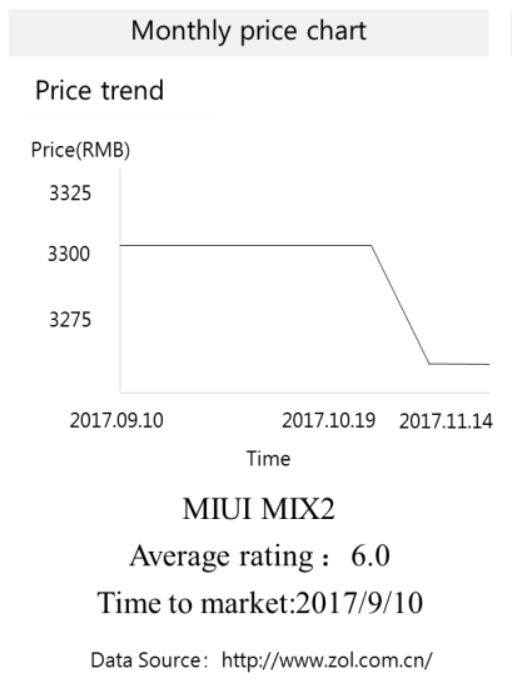

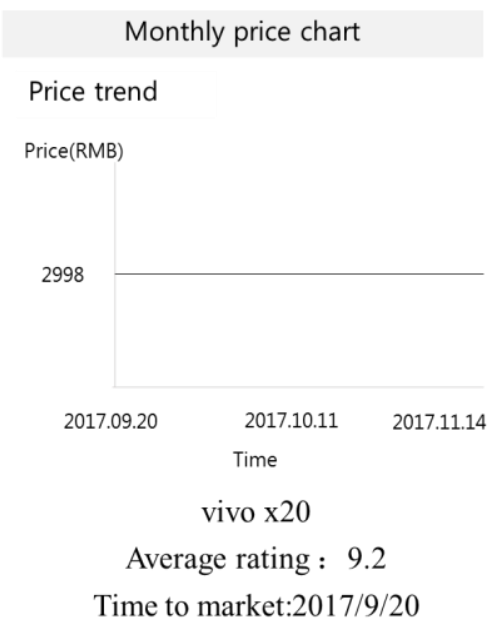

Time to market:2017/9/20

Figure 1: Price trends for different mobile phone brands

Empirical studies show that online reviews are more influential for games whose customization is lower and players have greater Internet experience [45]. The firm can design different consumer review systems and make different product pricing strategies for niche product, neutral product and mainstream product [24]. The degree of product customization fundamentally changes the way that a firm reacts to online consumer ratings. For example, Figure 2 shows that the adjustments in prices for different types of mobile phones are different even though the consumer ratings are the same. In particular, Samsung GALAXY A8 is designed for majority consumers and it is a mainstream product, while Razer Phone is for specific people who always play phone games and it is a niche product. 


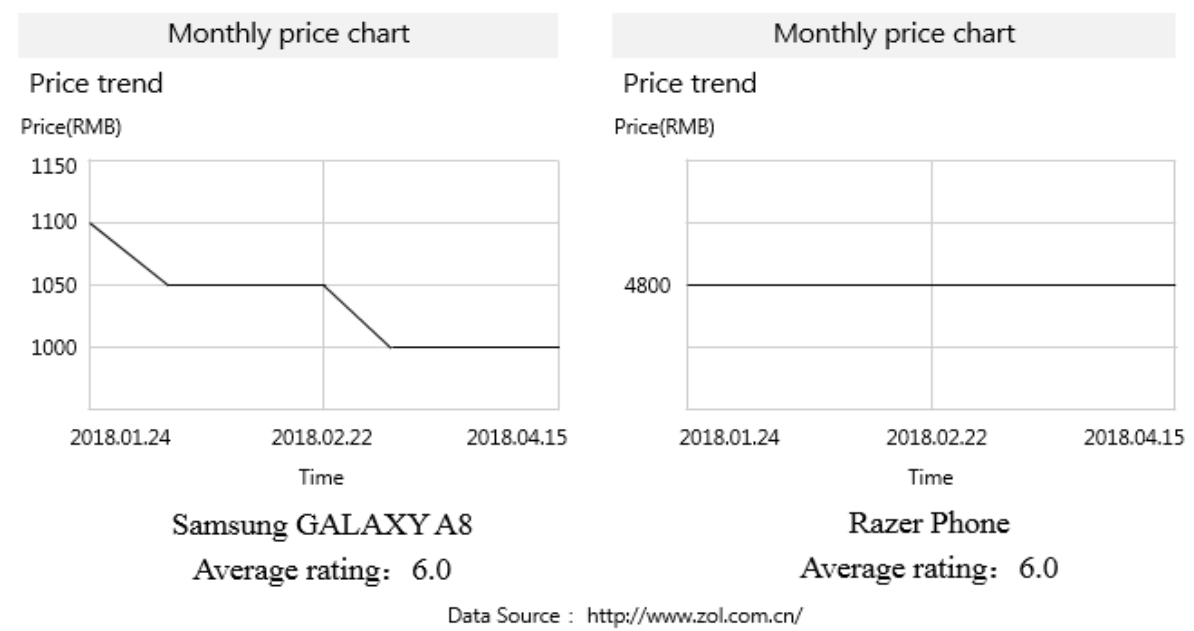

Figure 2: Varying prices for different mobile phone brands with the same online consumer rating

In this paper, we attempt to answer the following research questions. How should a firm adjust its pricing strategies according to the degree of its product customization? How does a firm strategically set price in response to consumer ratings? How do product customization and consumer ratings jointly impact a firm's pricing strategies? We study these research questions by a stylized game theoretic model in which a firm sells a product (niche, mainstream or neutral) to consumers over two periods. The quality of the product is uncertain to consumers, but it can be partially revealed to the second-period consumers by the online rating generated by the first-period consumers.

In addition to the business practice shown in Figures 1 and 2, our study is also motivated by three findings in the literature. First, the literature shows that online consumer ratings influence consumers' decisions and hence the sales (e.g., [15], [22]), Second, existing studies find that firms adjust price strategies in response to online reviews from both analytical and empirical perspectives (e.g., [9], [24], [30], [33], [36]). Third, extant research also shows that product mainstream level (i.e., the degree of product customization) can moderate the impact of online consumer reviews on sales (e.g., [39], [45]). Motivated by these three findings, our study intends to investigate the interplay among pricing, online consumer ratings, and product customization degree. We are particularly interested in how a firm adjusts its pricing strategy according to its product type in response to the presence of online consumer reviews.

The rest of this paper is organized as follows. Section 2 reviews the related literature. Section 3 presents the fundamental model and assumptions without consumer reviews and with consumer reviews. Section 4 discusses the firm's optimal pricing strategy when selling niche product, neutral product and mainstream product. Finally, in Section 5 we summarize the main points of this paper and discuss important managerial implications of our findings.

\section{Literature Review}

Many existing empirical studies have shown evidences that online consumer reviews play a key role on the purchase behavior of consumers. These reviews provide consumers with additional information so they can estimate a more accurate product value and make purchase decision based on their updated net utilities. The online sellers must adjust their pricing strategies to align with consumer reviews.

\subsection{The Impact of Online Consumer Reviews on Consumer Behavior and Sales}

The impacts of online consumer reviews on consumers' buying intentions have been widely studied in literature [19], [21], [32], [42]. The impact of online reviews on consumer purchasing decisions can vary depending on the product category and we elaborate as follows. Online reviews of tourists have an important influence on the accommodation decisions of other tourists while have little influence on their travel routes [16]. As for travel and financial services, people are more likely to choose search engine or follow the recommendation from family and friends [5]. Online reviews also impact the movie industry, digital microproducts, software and book [1]. Different reviews will affect consumers differently, and negative online reviews have a greater impact on high-risk adverse travelers than positive reviews. For positive online reviews, high-risk adverse travelers feel that the reviews posted by professionals, travel product images and well-known brand names are useful [4]. Through double-process theory and uncertainty theory, [6] focuses on how online consumer reviews affect consumer uncertainty and values. The results show that the review quality, the sources credibility and the prior belief will reduce consumer's uncertainty about the product. As the reduction in uncertainty affected value perception, the study shows that businesses will benefit if they provide online consumer reviews on their websites to reduce consumer uncertainty. The textual content of the product reviews is an important determinant of consumer choice when nesting text mining into the consumer choice model, exceeding the 
rank and number of comments [2]. The online reviews from personal-blogger reviews are most influential on product sales among seller-site, seller-blogger, and personal-blogger reviews.

Many studies show that consumers' purchasing behaviors and attitudes can be affected after the online reviews are observed, but what is its mechanism? Some related research has been done. The impact of online reviews on consumer choice of hotels is studied [23]; it is shown that online consumer review can increase consumer awareness of hotels, and that positive reviews produce positive attitude to the hotel and negative reviews lead to negative attitude [23]. Online consumer reviews play an indirect role by influencing consumer beliefs [38]. Online product reviews and product knowledge can affect online shopping attitudes, resulting in online shopping behavior. The related finding is that online reviews enable consumers to gain more product knowledge and thus make consumers more confident about online shopping [18]. The impact of the format of online consumer reviews is studied in [25], which shows that consumers' buying intentions increase when consumer ratings are presented in terms of average points. The impacts of online consumer reviews on experience-goods and search-goods are different: when consumers buy search-goods, their purchasing decisions are less affected by consumer reviews, while when consumers buy experience-goods, their purchasing decisions are greatly influenced by consumer reviews, and the higher the price of the goods, the greater the impact on them [41].

\subsection{Firms' Performance and Strategy in Response to Online Consumer Reviews}

Online reviews of books sold on Amazon and Barnes \& Noble show that customer reviews are overwhelmingly positive on both sites, and the impact of negative reviews on sales was greater than positive reviews [10]. The study of the beer industry finds that while the highest ratings are a good predictor of rapidly growing future sales, the presence of poor ratings is not a good predictor of poor sales [11]. Firms can use the number of online reviews to forecast box office revenue prior to the release of early box office results, and firms can also use online review data to generate estimates of competitor sales [13]. A study shows that the impact of consumer reviews on product sales decreased over time [22]. The amount of reviews has a significant impact on early sales of these new products and the effect is reducing over time in electronic and video games [12]. Quality information generated by consumers often aggravates supplier's competition and reduces their profits while increasing retailer's profits [8]. The effect of online product reviews on different players in a channel structure is investigated [28]. A study shows how firms can use the upstream pricing scheme as a strategic tool to benefit from online product reviews [29].

Our study is broadly related to the literature on the inference of users' attitude via collecting users' records on webpages. This stream of research focuses on the analysis of user behavior and user interest with the user feedbacks automatically tracked by search engines [3], [14]. In contrast, the consumer feedbacks in our model are generated by consumers themselves and hence are impacted by the pricing strategies. In addition, the focus of our study is quite different from the aforementioned literature, as we focus on how the pricing strategy depends on the product customization degree.

\subsection{Dynamic Pricing in the Presence of Online Consumer Reviews}

Our study is mostly related to dynamic pricing that has been widely applied in practice to align with information updating or market variation. Consumer rating, as a digital indicator of online consumer reviews, is more intuitive than textual information and has a significant impact on the pricing strategy of firms, and thus some scholars study the relationship between ratings and dynamic pricing. The theoretical model developed in [38] shows that when the average rating of a product is low, the greater variance in ratings, the higher the sales of the product. A model is established to study how the early consumer's assessment of product value is passed to later stage consumers through consumer ratings; the results show that firms should choose different pricing strategies to maximize their profits based on whether consumers are able to observe the product's history price and market growth rate of the product [31]. The choice of whether or not to adopt an online review system as well as the optimal price should depend on the value and prevalence of the product [24].

Online consumer reviews have an impact on a firm's dynamic pricing strategies and profitability [8], [20], [27], [30] [33], [34], [35], [36], [37]. The investigation of online consumer reviews of third-party platforms shows that if consumers value products more rather than service, firms should choose advertising strategies rather than pricing strategies to deal with online consumer reviews [8]. Pre-announce price strategy against dynamical pricing strategy are compared in a two-phase model when a monopolist faces strategic consumers [37]. The online book reviews published on Amazon (Site 2) show that companies can encourage consumers to generate positive online reviews in the early stages of new product sales through product prices, advertisements, or product designs to obtain greater benefits [33]. If a firm can dynamically adjust its price based on consumer-generated quality information when facing strategic consumers, the pricing strategy at an initial stage not only affects the sales in the initial stage, but also passes information about product quality to the later stage through consumer reviews [27]. An analytical model is developed to examine the impact of price-influenced reviews on firm optimal pricing and consumer welfare; the results suggest that firms can boost ratings of their products at release via low introductory pricing [34]. The optimal pricing strategy for a platform selling electronic products when consumers sequentially learn about product quality from consumer reviews is investigated [20]. Applying sentiment analysis and spatial autoregressive model to data from Airbnb, it is 
shown that rental prices are influenced by online review scores [30]. More positive online customer ratings can increase prices and online sales [36].

Many scholars have studied the influence of online consumer reviews on consumer buying behavior and firm strategy, but most of the studies ignore the degree of product customization [27], [40], [43]. We will classify the products into three types, niche products, neutral product and mainstream product, and further investigate the impact of online consumer ratings on firm's pricing strategy for different product types.

\section{Model Setup}

In this section, we set up the model and introduce the game between the firm and consumers. We consider two cases, with and without online consumer ratings.

\subsection{Basic Model and Assumption}

In this section, we establish a game theoretic model, by which we study a firm's pricing strategies in the presence of online consumer ratings, and the impact of the degree of product customization on pricing. In particular, a firm sells its product online over two periods, $t=1,2$. The product is durable, and consumers do not repeatedly buy the product within a short time. So there are two independent groups of consumers, with one group arriving in the first period and the other arriving in the second period. The total number of consumers in each period is normalized to one.

Consumers are uncertain about the product value. The firm (e.g. an online seller) provides consumers with only a virtual description of the product, using texts, graphics, or symbols in a paper or web page catalog. Consumers can evaluate part of the product value through such posted information, and we call this sort of product value observable value. However, this eliminates the use of touch, taste, smell, and often sound from the set of senses used in the prepurchase evaluation and can cause evaluation uncertainties by shoppers. We call this nontransparent product value unobservable value. These unobservable product value become known by consumers after they purchase and use the products. For example, products like the electronic devices, apparel, books, games, and so on, cannot be fully described online by the seller, and a consumer usually cannot thoroughly sense the value of the product unless he buys one.

Without an online rating system, consumers in both periods make their purchasing decisions based on the observable value. When an online consumer rating system is deployed by the firm, online consumer rating will be generated by all consumers who purchase in the first period and will affect consumers' purchasing decision in the second period. That is, consumers in the second period will update their perception of unobservable product value based on the average consumer rating. So in this study we will explore how a consumer updates the product value and how the firm adjusts its second period price when considering online consumer reviews.

The consumers are heterogeneous in terms of their preferences over the product. For example, each consumer has different tastes for the color of a mobile phone cover. To model such idiosyncratic misfit between a consumer and the product, we employ the traditional Hotelling model in which the heterogeneous consumers are uniformly distributed on the line segment $[0,1]$, and each consumer has a location on this line segment. In fact, the location of a consumer measures how the product misfit with him, a larger $x(x \in[0,1])$ means the product is less fit to the consumer. Thus, consumers incur misfit costs: a consumer who is located at $x \in[0,1]$ (called consumer $x$ hereafter) incurs a cost of misfit with the product, $c x$, where $c$ is the unit misfit cost. As $c$ does not qualitatively affect the company's pricing strategy, we normalize it to 1 . The probability density function of $x$ is denoted by $f(x)$, which characterizes the degree of product customization. Mainstream products have low degree of product customization and broad appeal, so more consumers have a short distance to the product (i.e., $x$ is more likely close to zero). Niche products have high degree of product customization and narrow appeal, so more consumers have a long distance to the product (i.e., $x$ is more likely close to one). As for neutral products, its misfit distance are evenly distributed among consumers. The explicit forms of $f(x)$ for different degrees of product customization will be specified in Section 4.

In period $t(t=1,2)$, each consumer will purchase at most one unit of product and obtain the net utility

$$
U(x)=v+\varepsilon-x-p_{t}
$$

where $v$ is the common observable value shared by all consumers, $\varepsilon$ is the unobservable value, $x$ is the location of the consumer which is also interpreted as consumer $x$ 's misfit to the product, and $p_{t}$ is the product price in time period $t$. The first two terms $(v+\varepsilon)$ is related to the product quality (also called vertical attribute in the literature), and every consumer prefers higher quality. The third term $(x)$ is related to an individual consumer's preference over the product (also called horizontal attribute in the literature). Consumer $x$ will buy the product if $U(x) \geq 0$ and will exit the market with zero utility otherwise. The unobservable value (i.e. $\varepsilon$ ), which is assumed to be uniformly distributed in $[-1,1]$, is 
unknown to the consumers before they make the purchase. The consumer can perceive the unobservable value $\varepsilon$ only after purchasing and using the product. We focus on observable value $v \in[1,2]$. This is to exclude uninteresting cases: if $v<1$, the product value $v+\varepsilon$ can be negative, while if $v>2$, the firm's pricing strategy does not change with online ratings.

\subsection{Without Online Consumer Ratings}

When there are not consumer ratings, in each selling period, the consumers can only make their purchase decisions based on the observable value and the expectation of the unobservable value, which is $E(\varepsilon)=0$. The utility function of a consumer $x$ is $U(x)=v-x-p_{t}$, which means consumers with $x \leq v-p_{t}$ will purchase the product. When no consumer ratings are available, consumers in the second time period will not get any information updating from previous experienced consumers. Their purchasing decisions will remain the same and so is the firm's pricing strategy. The market demand in each period is

$$
D_{t}\left(p_{t} ; v\right)=\int_{0}^{v-p_{t}} f(x) d x
$$

and the firm's profit in each period is

$$
\pi_{t}\left(p_{t} ; v\right)=D_{t}\left(p_{t} ; v\right) p_{t}
$$

\subsection{With Online Consumer Ratings}

When there are consumer ratings, the firm has the incentive to set a lower price than $v_{\min }=1$ in the first period to get a higher consumer average rating, so as to get more profit due to higher consumer perceived product value in the second stage.

The unobservable value $\varepsilon$ will be realized to consumers who purchase the product in the first period. The ex post utility function of consumer $x$ will be $U^{\prime}(x)=v+\varepsilon-x-p_{1}$. Then, consumer $x$ will post his individual rating online based on the value of $U^{\prime}(x)$. Consumer $x$ will post high rating (satisfied), which we assume is 1 , if his utility $U^{\prime}(x) \geq 0$, otherwise, consumer $x$ will post low rating (unsatisfied), which we assume is 0 . The binary rating model follows from [26], and allows us to neatly incorporate the degree of product customization. We refer to the number of consumers purchasing products and the number of consumers give a high rating in the first period as $D$ and $d$, respectively. Clearly, the average rating is $R=d / D$. And $D=\int_{0}^{v-p_{1}} f(x) d x$. If $\varepsilon \geq 0$, all consumers buying the product in the first period get positive utility and give the higher ratings, so $d=\int_{0}^{v-p_{1}} f(x) d x$ and the average rating $R=1$; If $-\left(v-p_{1}\right)<\varepsilon<0$, there are $\int_{0}^{v+\varepsilon-p_{1}} f(x) d x$ consumers buying the product in the first period get positive utility and give the higher ratings, so $d=\int_{0}^{v+\varepsilon-p_{1}} f(x) d x$ the average rating $R=\frac{\int_{0}^{v+\varepsilon-p_{1}} f(x) d x}{\int_{0}^{v-p_{1}} f(x) d x}$; when

$-1 \leq \varepsilon \leq-\left(v-p_{1}\right)$, all consumers buying the product in the first period get negative utility and give the lower ratings, so $d=0$ and the average rating $R=0$. So

$$
R= \begin{cases}1, & 0 \leq \varepsilon \leq 1 \\ \frac{\int_{0}^{v+\varepsilon-p_{1}} f(x) d x}{\int_{0}^{v-p_{1}} f(x) d x}, & -\left(v-p_{1}\right)<\varepsilon<0 . \\ 0, & -1 \leq \varepsilon \leq-\left(v-p_{1}\right) .\end{cases}
$$

When consumers in the second period see that $R=1(0<R<1$ or $R=0)$, the consumer can infer that $0 \leq \varepsilon \leq 1$ $\left(-\left(v-p_{1}\right)<\varepsilon<0\right.$ or $\left.-1 \leq \varepsilon \leq-\left(v-p_{1}\right)\right)$, and they know that $\varepsilon$ is uniformly distributed in $[-1,1]$, so they can use $R$ to updated expectation of $\varepsilon$ in the second period will be

$$
E\left[\varepsilon \mid p_{1}, R\left(p_{1} ; v, \varepsilon\right)\right]=\frac{1}{2}\left(E\left[\varepsilon \mid p_{1}, R\left(p_{1} ; v, \varepsilon\right)\right]=\varepsilon\left(p_{1}, v, R\right) \text { or } E\left[\varepsilon \mid p_{1}, R\left(p_{1} ; v, \varepsilon\right)\right]=\frac{1-\left(v-p_{1}\right)}{2}\right)
$$


The updated utility function of the consumers in the second period after observing average consumer rating is

$$
U^{\prime \prime}(x)=v+E\left[\varepsilon \mid p_{1}, R\left(p_{1} ; v, \varepsilon\right)\right]-x-p_{2} .
$$

All consumers whose misfits satisfy $x \leq v+E\left[\varepsilon \mid p_{1}, R\left(p_{1} ; v, \varepsilon\right)\right]-p_{2}$ will buy the products. Market demand in the second period will be

$$
D_{2}\left(p_{2} ; v, R\left(p_{1} ; v, \varepsilon\right)\right)=\int_{0}^{v+E\left[\varepsilon \mid p_{1}, R\left(p_{1} ; v, \varepsilon\right)\right]-p_{2}} f(x) d x
$$

the firm's profit in the second period is

$$
\pi_{2}\left(p_{2} ; v, R\left(p_{1} ; v, \varepsilon\right)\right)=D_{2}\left(p_{2} ; v, R\left(p_{1} ; v, \varepsilon\right)\right) p_{2}
$$

By (6), we can derive the firm's optimal price in the second period, the specific form of which will be presented in Section 4. The total expected profit of the firms is

$$
E[\pi]=\pi_{1}\left(p_{1} ; v\right)+E\left[\pi_{2}^{*}\right]
$$

where $E\left[\pi_{2}^{*}\right]$ is the firm's optimal expected profit at the optimal second-period price obtained by (6).

\section{Firms' Optimal Pricing Strategies for Different Types of Products}

In this section, we investigate the impact of the degree of product customization on the firm's pricing strategy. We use backward induction to solve the model presented in Section 3.

\subsection{Niche Product}

When a firm sells niche products, the degree of misfit will be large for a majority of consumers. To characterize this feature and for analytical tractability, we assume that $f(x)=2 x$. We use superscript ${ }^{N I}$ to denote the niche product, and use subscript ${ }_{N}$ and ${ }_{R}$ to denote without online consumer ratings and with online consumer ratings respectively. For example, $p_{N, t}^{N I}$ represents the niche product price in period $t$ without online consumer reviews. Without online consumer ratings, the market demand in period $t$ is

$$
D_{N, t}^{N I}\left(p_{N, t}^{N \prime} ; v\right)=\int_{0}^{v-p_{N, t}^{N \prime}} 2 x d x
$$

the firm maximizes the profit in period 1 and period 2

$$
\max \sum_{t=1}^{2} \pi_{N, t}^{N I}\left(p_{N, t}^{N I} ; v\right)=\max \sum_{t=1}^{2} p_{N, t}^{N I}\left(v-p_{N, t}^{N /}\right)^{2}
$$

By solving (9), we can obtain the optimal pricing strategy

$$
p_{N, 1}^{N /^{*}}=p_{N, 2}^{N *^{*}}=\frac{v}{3}
$$

the profits in each period and the total profit will be, respectively,

$$
\pi_{N, 1}^{N l^{*}}=\pi_{N, 2}^{N l^{*}}=\frac{4 v^{3}}{27}
$$

And

$$
\pi_{N}^{N \prime^{*}}=\frac{8 v^{3}}{27}
$$


With online consumer ratings, we can get the $R$ is as following

$$
R= \begin{cases}1, & 0 \leq \varepsilon \leq 1 \\ \frac{\left(v-p_{R, 1}^{N I}+\varepsilon\right)^{2}}{\left(v-p_{R, 1}^{N I}\right)^{2},} & -\left(v-p_{R, 1}^{N I}\right)<\varepsilon<0 \\ 0, & -1 \leq \varepsilon \leq-\left(v-p_{R, 1}^{N I}\right)\end{cases}
$$

and the second-period consumers update $\varepsilon$ according to $R$ as following

$$
E\left[\varepsilon \mid p_{R, 1}^{N I}, R\left(p_{R, 1}^{N I} ; v, \varepsilon\right)\right]= \begin{cases}\frac{1}{2}, & R=1 \\ -\left(1-R^{\frac{1}{2}}\right)\left(v-p_{R, 1}^{N I}\right), & 0<R<1 . \\ \frac{1-\left(v-p_{R, 1}^{N I}\right)}{2}, & R=0\end{cases}
$$

The utility function for consumers in second period is $U^{\prime \prime}(x)=v+E\left[\varepsilon \mid p_{R, 1}^{N I}, R\left(p_{R, 1}^{N I} ; v, \varepsilon\right)\right]-x-p_{R, 2}^{N I}$, and the demand function is

$$
D_{R, 2}^{N I}\left(p_{R, 2}^{N I} ; v, R\right)= \begin{cases}\left(\frac{1}{2}+v-p_{R, 2}^{N I}\right)^{2}, & R=1 \\ \left(v-p_{R, 2}^{N I}-\left(1-R^{\frac{1}{2}}\right)\left(v-p_{R, 1}^{N I}\right)\right)^{2}, & 0<R<1 . \\ \left(\frac{v+p_{R, 1}^{N I}-1}{2}-p_{R, 2}^{N I}\right)^{2}, & R=0\end{cases}
$$

Market demand in period 1 is

$$
D_{R, 1}^{N \prime}\left(p_{R, 1}^{N \prime} ; v\right)=\int_{0}^{v-p_{R, 1}^{N \prime}} 2 x d x
$$

The firm maximizes the expected profits in period 1 and period 2

$$
\begin{aligned}
& \max \left\{\pi_{R, 1}^{N I}\left(p_{R, 1}^{N I} ; v\right)+E\left[\pi_{R, 2}^{N I^{*}}\left(p_{R, 2}^{N I} ; v\right)\right]\right\}=\max \left\{p_{R, 1}^{N I}\left(v-p_{R, 1}^{N I}\right)^{2}+\frac{2}{27}\left(\frac{1}{2}+v\right)^{3}+\right. \\
& \left.\int_{0}^{1} \frac{2\left(v-p_{R, 1}^{N I}\right)}{27}\left(v-\left(1-R^{\frac{1}{2}}\right)\left(v-p_{R, 1}^{N I}\right)\right)^{3} d R+\frac{2\left(1-v+p_{R, 1}^{N I}\right)}{27}\left(\frac{v+p_{R, 1}^{N I}-1}{2}\right)^{3}\right\}
\end{aligned}
$$

By solving (15), We can obtain the optimal pricing strategy: when $1 \leq v \leq \frac{80985^{\frac{1}{2}}}{20}-\frac{51}{4}$, we can find $P^{0} \in\left(v-1, \frac{v}{3}\right)$ and $\left.\frac{\partial\left\{\pi_{R, 1}^{N I}\left(p_{R, 1}^{N I} ; v\right)+E\left[\pi_{R, 2}^{N I^{*}}\left(p_{R, 2}^{N I} ; v\right)\right]\right\}}{\partial p_{R, 1}^{N I}}\right|_{p_{R, 1}^{N I}=P^{0}}=0$.

$$
p_{R, 1}^{N t^{*}}= \begin{cases}P^{0}, & 1 \leq v \leq \frac{80985^{\frac{1}{2}}}{20}-\frac{51}{4}, \\ v-1, & \frac{80985^{\frac{1}{2}}}{20}-\frac{51}{4}<v \leq 2\end{cases}
$$




$$
p_{R, 2}^{N /^{*}}= \begin{cases}\frac{v+p_{R, 1}^{N /^{*}}-1}{6}, & R=0 \\ \frac{1}{3}\left(v-\left(1-R^{\frac{1}{2}}\right)\left(v-p_{R, 1}^{N /^{*}}\right)\right), & 0<R<1 . \\ \frac{1}{3}\left(v+\frac{1}{2}\right), & R=1\end{cases}
$$

Proposition 1: For the niche product, $p_{R, 1}^{N I^{*}}<p_{N, 1}^{N I^{*}}$ when $1 \leq v<\frac{3}{2}$ and $p_{R, 1}^{N I^{*}} \geq p_{N, 1}^{N I^{*}}$ when $\frac{3}{2} \leq v \leq 2$.

Proposition 1 implies that, for the niche product, when taking online consumer ratings into consideration, the firm will reduce its selling price in the first period if the observable value of the niche product is relatively low and will raise its selling price otherwise.

For niche products, a majority of the consumers' net utilities will be relatively low due to large misfit distances. When the observable value of a niche product is relatively low, consumers in the first stage are more likely to get less utilities and give lower ratings, which will result in a lower estimate of unobservable value for consumers in the second period. This effect will hurt the sales of the second period. Therefore, when the observable value is low, the company should set a lower price in the first period to induce a higher average consumer rating, which builds belief of higher unobservable value. Thus, the profit in the second period will benefit from such strategic decision in the first period. In contrast, when the observable value is high, it is more likely for consumers in the first period to obtain a positive utility after the unobservable value is realized. Therefore, the firm can set a higher price in the first period to obtain higher profit in the first period without hurting the second period sales dramatically.

Proposition 2: For the niche product, $E\left[p_{R, 2}^{N)^{*}}\right]>p_{R, 1}^{N /^{*}}$ when $1 \leq v<\frac{37}{24}$; and $E\left[p_{R, 2}^{N)^{*}}\right] \leq p_{R, 1}^{N /^{*}}$ when $\frac{37}{24} \leq v \leq 2$.

The expectation of the optimal price in the second period is higher (lower) than the optimal price in the first period if the observable value is relatively low (high).

This result is consistent with Proposition 1. When the value of niche product is relatively low, the firm will strategically set a lower selling price in the first period to induce a higher consumer rating. This leads to a belief of higher unobservable value for the consumers in the second period. Therefore, the expectation of the optimal profit of the second period will also increase. In contrast, when the observable value is high, the firm will adjust its strategy, i.e. setting higher selling price in the first period.

\subsection{Neutral Product}

To characterize this product feature and for analytical tractability, we assume that $f(x)=1$. We use superscript.$^{N E}$ to denote the neutral product, and use subscript $\cdot_{N}$ and ${ }_{R}$ to denote without online consumer ratings and with online consumer ratings, respectively. Without online consumer ratings, the market demand in period $t$ is

$$
D_{N, t}^{N E}\left(p_{N, t}^{N E} ; v\right)=\int_{0}^{v-p_{N, t}^{N E}} 1 d x
$$

the firm maximizes the profit in period 1 and period 2

$$
\max \sum_{t=1}^{2} \pi_{N, t}^{N E}\left(p_{N, t}^{N E} ; v\right)=\max \sum_{t=1}^{2} p_{N, t}^{N E}\left(v-p_{N, t}^{N E}\right)
$$

We can obtain the optimal pricing strategy by solving (23)

$$
p_{N, 1}^{N E^{*}}=p_{N, 2}^{N E^{*}}=\frac{v}{2}
$$

the profits in each period and the total profit will be

$$
\pi_{N, 1}^{N E^{\star}}=\pi_{N, 2}^{N E^{\star}}=\frac{v^{2}}{4}
$$


and

$$
\pi_{N}^{N E^{*}}=\frac{v^{2}}{2}
$$

With online consumer ratings, we can get the $R$ is as following

$$
R= \begin{cases}1, & 0 \leq \varepsilon \leq 1 \\ \frac{v-p_{R, 1}^{N E}+\varepsilon}{v-p_{R, 1}^{N E}}, & -\left(v-p_{R, 1}^{N E}\right)<\varepsilon<0, \\ 0, & -1 \leq \varepsilon \leq-\left(v-p_{R, 1}^{N E}\right)\end{cases}
$$

and the second-period consumers update $\varepsilon$ according to $R$ as following

$$
E\left[\varepsilon \mid p_{R, 1}^{N E}, R\left(p_{R, 1}^{N E} ; v, \varepsilon\right)\right]= \begin{cases}\frac{1}{2}, & R=1 \\ -(1-R)\left(v-p_{R, 1}^{N E}\right), & 0<R<1 . \\ \frac{1-\left(v-p_{R, 1}^{N E}\right)}{2}, & R=0\end{cases}
$$

The utility function for consumers in second period is $U^{\prime \prime}(x)=v+E\left[\varepsilon \mid p_{R, 1}^{N E}, R\left(p_{R, 1}^{N E} ; v, \varepsilon\right)\right]-x-p_{R, 2}^{N E}$, and the demand function is

$$
D_{R, 2}^{N E}\left(p_{R, 2}^{N E} ; v, R\right)= \begin{cases}\frac{1}{2}+v-p_{R, 2}^{N E}, & R=1 \\ v-p_{R, 2}^{N E}-(1-R)\left(v-p_{R, 1}^{N E}\right), & 0<R<1, \\ \frac{v+p_{R, 1}^{N E}-1}{2}-p_{R, 2}^{N E}, & R=0\end{cases}
$$

and market demand in period 1 is

$$
D_{R, 1}^{N E}\left(p_{R, 1}^{N E} ; v\right)=\int_{0}^{v-p_{R, 1}^{N E}} 1 d x
$$

The firm maximizes the expected profit in period 1 and period 2

$$
\begin{aligned}
& \max \left\{\pi_{R, 1}^{N E}\left(p_{R, 1}^{N E} ; v\right)+E\left[\pi_{R, 2}^{N E^{\star}}\left(p_{R, 2}^{N E} ; v\right)\right]\right\}=\max \left\{p_{R, 1}^{N E}\left(v-p_{R, 1}^{N E}\right)+\frac{(2 v+1)^{2}}{32}+\right. \\
& \left.\int_{0}^{1} \frac{v-p_{R, 1}^{N E}}{8}\left(v-(1-R)\left(v-p_{R, 1}^{N E}\right)\right)^{2} d R+\frac{\left(1-v+p_{R, 1}^{N E}\right)\left(v+p_{R, 1}^{N E}-1\right)^{2}}{32}\right\}
\end{aligned}
$$

We can obtain the optimal pricing strategy by solving (31)

$$
\begin{aligned}
& \pi_{p, 1}^{N E *}=v+16\left(\frac{17}{4}-\frac{v}{8}\right)^{\frac{1}{2}}-33, \\
& p_{R, 2}^{N E^{*}}= \begin{cases}\frac{v+p_{R, 1}^{N E^{*}}-1}{4}, & R=0 \\
\frac{\left(v-(1-R)\left(v-p_{R, 1}^{N E^{*}}\right)\right)}{2}, & 0<R<1 . \\
\frac{2 v+1}{4}, & R=1\end{cases}
\end{aligned}
$$


Proposition 3: For the neutral product, $p_{R, 1}^{N E^{\star}}<p_{N, 1}^{N E^{\star}}$ for all $1 \leq v \leq 2$.

For the neutral product, the optimal price in the first period with online consumer ratings is lower than the optimal price in the first period without online consumer ratings.

Proposition 4: For the neutral product, $p_{R, 1}^{N E^{\star}}>E\left[p_{R, 2}^{N E^{*}}\right]$ for all $1 \leq v \leq 2$.

For the neutral product, the expectation of the optimal price in the second period is higher than the optimal price in the first period when considering consumer ratings.

As for neutral products, consumers are evenly distributed over the misfit line, so their assessments of the total value of the product will affect aggregate demand linearly. Therefore, regardless of the value of the product, when considering consumer ratings generated in the first period, the firm will set a lower price to obtain a higher rating so as to increase the consumers' estimate of the product value in the second period. Therefore, the firm sets a higher price in the second period to take advantage of the reputation built in the first period to achieve a higher total profit.

\subsection{Mainstream Product}

When a firm sells mainstream product, the product can meet the needs of a large portion of consumers, i.e. the degree of misfit will be small for a majority of consumers. To characterize this feature and for analytical tractability, we assume that $f(x)=2-2 x$. We use superscript ${ }^{M}$ to denote the mainstream product, and use subscript ${ }_{N}$ and ${ }_{R}$ to denote without online consumer ratings and with online consumer ratings, respectively. Without online consumer ratings, the market demand in period $t$ is

$$
D_{N, t}^{M}\left(p_{N, t}^{M} ; v\right)=\int_{0}^{v-p_{N, 1}^{M}}(2-2 x) d x
$$

the firm maximizes the profit in period 1 and period 2

$$
\max \sum_{t=1}^{2} \pi_{N, t}^{M}\left(p_{N, t}^{M} ; v\right)=\max \sum_{t=1}^{2} p_{N, t}^{M}\left(v-p_{N, t}^{M}\right)\left(2-v+p_{N, t}^{M}\right)
$$

We can obtain the optimal pricing strategy by solving (35)

$$
p_{N, 1}^{M^{*}}=p_{N, 2}^{M^{*}}=\frac{2 v+\left(v^{2}-2 v+4\right)^{\frac{1}{2}}-2}{3},
$$

the profits in each period and the total profit will be

$$
\pi_{N, 1}^{M^{*}}=\pi_{N, 2}^{M^{*}}=\frac{4 v}{9}+\frac{2\left(v^{2}-2 v+4\right)^{\frac{3}{2}}}{27}+\frac{2 v^{2}}{9}-\frac{2 v^{3}}{27}-\frac{16}{27},
$$

and

$$
\pi_{N}^{M^{*}}=\frac{8 v}{9}+\frac{4\left(v^{2}-2 v+4\right)^{\frac{3}{2}}}{27}+\frac{4 v^{2}}{9}-\frac{4 v^{3}}{27}-\frac{32}{27}
$$

With online consumer ratings, we can get the $R$ is as following

$$
R=\left\{\begin{array}{ll}
1, & 0 \leq \varepsilon \leq 1 \\
\frac{\left(v-p_{R, 1}^{M}+\varepsilon\right)\left(2-v+p_{R, 1}^{M}-\varepsilon\right)}{\left(v-p_{R, 1}^{M}\right)\left(2-v+p_{R, 1}^{M}\right)}, & -\left(v-p_{R, 1}^{M}\right)<\varepsilon<0, \\
0, & -1 \leq \varepsilon \leq-\left(v-p_{R, 1}^{M}\right)
\end{array},\right.
$$


and the second-period consumers update $\varepsilon$ according to $R$ as following

$$
E\left[\varepsilon \mid p_{R, 1}^{M}, R\left(p_{R, 1}^{M} ; v, \varepsilon\right)\right]= \begin{cases}\frac{1}{2}, & R=1 \\ 1-\left(v-p_{R, 1}^{M}\right)-Q, & 0<R<1 \\ \frac{1-\left(v-p_{R, 1}^{M}\right)}{2}, & R=0\end{cases}
$$

We write that $Q=\left(R p_{R, 1}^{M 2}-2 R p_{R, 1}^{M} v+2 R p_{R, 1}^{M}+R v^{2}-2 R v+1\right)^{\frac{1}{2}}$. The utility function for consumers in second period is $U^{\prime \prime}(x)=v+E\left[\varepsilon \mid p_{R, 1}^{M}, R\left(p_{R, 1}^{M} ; v, \varepsilon\right)\right]-x-p_{R, 2}^{M}$, and the demand function is

$$
D_{R, 2}^{M}\left(p_{R, 2}^{M} ; v, R\right)= \begin{cases}\left(\frac{1}{2}+v-p_{R, 2}^{M}\right)\left(\frac{3}{2}-v+p_{R, 2}^{M}\right), & R=1 \\ \left(1+p_{R, 1}^{M}-Q-p_{R, 2}^{M}\right)\left(1-p_{R, 1}^{M}+Q+p_{R, 2}^{M}\right), & 0<R<1, \\ \left(\frac{v+p_{R, 1}^{M}-1}{2}-p_{R, 2}^{M}\right)\left(\frac{5-v-p_{R, 1}^{M}}{2}+p_{R, 2}^{M}\right), & R=0\end{cases}
$$

and market demand in period 1 is

$$
D_{R, 1}^{M}\left(p_{R, 1}^{M} ; v\right)=\int_{0}^{v-p_{R, 1}^{M}}(2-2 x) d x
$$

The firm maximizes the expected profit in period 1 and period 2

$$
\begin{aligned}
& \max \left\{\pi_{R, 1}^{M}\left(p_{R, 1}^{M} ; v\right)+E\left[\pi_{R, 2}^{M^{*}}\left(p_{R, 2}^{M} ; v\right)\right]\right\}=\max \left\{p_{R, 1}^{M}\left(v-p_{R, 1}^{M}\right)\left(2-v+p_{R, 1}^{M}\right)+\right. \\
& \frac{1-v+p_{R, 1}^{M}}{2}\left(\frac{2\left(v+p_{R, 1}^{M}-1\right)}{9}+\frac{\left(\left(v+p_{R, 1}^{M}-1\right)^{2}-8\left(v+p_{R, 1}^{M}-1\right)+16\right)^{\frac{3}{2}}}{108}+\right. \\
& \left.\frac{\left(v+p_{R, 1}^{M}-1\right)^{2}}{18}-\frac{\left(v+p_{R, 1}^{M}-1\right)^{3}}{108}-\frac{16}{27}\right)+\frac{\left(v-p_{R, 1}^{M}\right)}{2} \cdot \int_{0}^{1}\left(\frac{4\left(3 p_{R, 1}^{M}-3 Q-1\right)}{9}+\right. \\
& \left.\frac{2\left(\left(1+p_{R, 1}^{M}-Q\right)^{2}-2\left(1+p_{R, 1}^{M}-Q\right)+4\right)^{\frac{3}{2}}}{27}+\frac{2\left(1+p_{R, 1}^{M}-Q\right)^{2}}{9}-\frac{2\left(1+p_{R, 1}^{M}-Q\right)^{3}}{27}\right) d R \\
& +\frac{1}{2}\left(\frac{12 v-10}{27}+\frac{2\left(4 v^{2}-4 v+13\right)^{\frac{3}{2}}}{108}+\frac{(2 v+1)^{2}}{18}-\frac{(2 v+1)^{3}}{108}\right)
\end{aligned}
$$

The analytical optimal solutions for the above problem are not available, we turn to numerical method to investigate the pricing behaviors in this case. By fixing a value of $v$ in function (35), we can obtain $p_{R, 1}^{M^{*}}$. We further compare $p_{R, 1}^{M^{*}}$ and $p_{N, 1}^{M^{*}}$ to summarize the following numerical findings.

Proposition 5: For the mainstream product, $p_{R, 1}^{M^{*}}>p_{N, 1}^{M^{*}}$ for all $1 \leq v \leq 2$.

As for mainstream products, most consumers are more likely to get a positive utility since their misfit distances are small. The firm can set a higher price in the first period to get higher profit without sacrificing the sales or consumer rating. According to the above two aspects, firms should set higher first-period price with consumer ratings.

Proposition 6: For the mainstream product, $E\left[p_{R, 2}^{M^{*}}\right]>p_{R, 1}^{M^{*}}$ if the observable value $v$ is relatively low, $E\left[p_{R, 2}^{M^{*}}\right] \leq p_{R, 1}^{M^{*}}$, otherwise.

When the value of the mainstream product is relatively low, the expectation of the optimal price in the second period is greater than the optimal price in the first period when considering online consumer ratings. When the value of the mainstream product is relatively high, the expectation of the optimal price of the second period is less than the optimal price in the first period when considering online consumer ratings.

When considering consumer ratings in mainstream product market, the firm has to lower the price to seduce a higher consumer rating if the observable value is small. This pricing strategy raises the consumers' expectation of the unobservable value in the second period. Therefore, the firm can raises the second-period price to derive higher total profit. When the observable value is large, the opposite is true. 
We also study consumer online rating's impaction on prices changing of niche product, neutral product and mainstream product. We refer to these changings as $\Delta p_{1}^{N I^{*}}, \Delta p_{1}^{N E^{*}}$ and $\Delta p_{1}^{M^{*}}$ respectively.

$$
\begin{aligned}
& \Delta p_{1}^{N I^{*}}=p_{R, 1}^{N I^{*}}-p_{N, 1}^{N I^{*},} \\
& \Delta p_{1}^{N E^{*}}=p_{R, 1}^{N E^{*}}-p_{N, 1}^{N E^{*}}, \\
& \Delta p_{1}^{M^{*}}=p_{R, 1}^{M^{*}}-p_{N, 1}^{M^{*}} .
\end{aligned}
$$

Proposition 7: When $1 \leq v \leq 48 \cdot 257^{\frac{1}{2}}-768 \quad, \quad \Delta p_{1}^{M^{*}}>\Delta p_{1}^{N E^{*}}>\Delta p_{1}^{N I^{*}} \quad ; \quad$ when $48 \cdot 257^{\frac{1}{2}}-768<v<v_{0} \quad$, $\Delta p_{1}^{M^{*}}>\Delta p_{1}^{N l^{*}}>\Delta p_{1}^{N E^{*}}$ and when $v_{0} \leq v \leq 2, \Delta p_{1}^{N I^{*}}>\Delta p_{1}^{M^{*}}>\Delta p_{1}^{N E^{*}}$.

The relationship between as $\Delta p_{1}^{N I^{*}}, \Delta p_{1}^{N E^{*}}$ and $\Delta p_{1}^{M^{*}}$ can be shown in the Figure 3 . When the observable value $v$ is relatively low, the consumer online rating has more significant impaction on neutral and mainstream product price changing, while the observable value $v$ is relatively higher, the consumer online rating has a more significant impact on niche product price change. But the impact of consumer online rating on the price change is more significant for mainstream product than for neutral product.

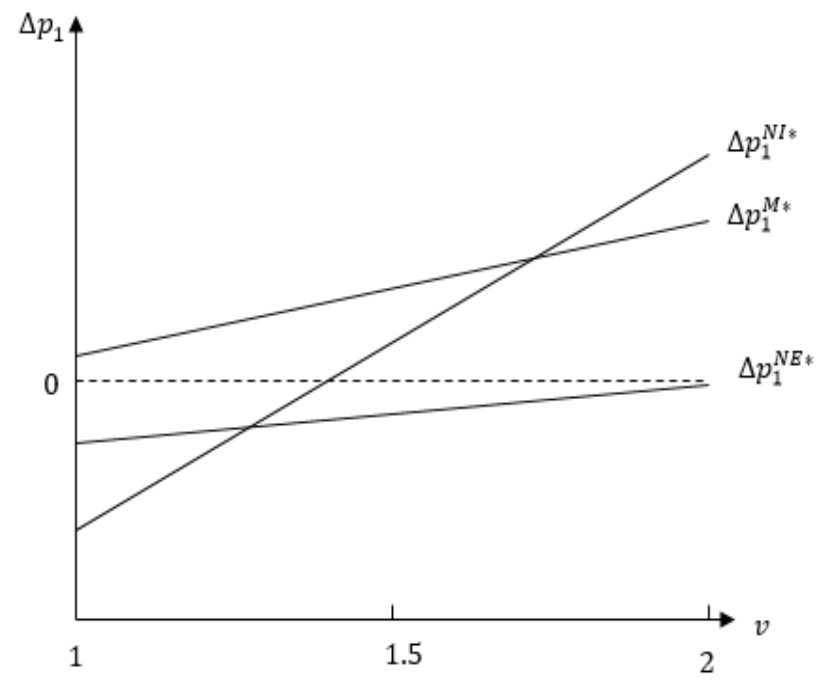

Figure3: The relationship between as $\Delta p_{1}^{N I^{\star}}, \Delta p_{1}^{N E^{\star}}$ and $\Delta p_{1}^{M^{*}}$

When considering consumer online rating, if average rating is too low the firm can reduce its product price to attract consumers to buy the products. We denote $R_{0}$ as the threshold that when the average rating is below it the firm should reduce its price, when the average rating is over it the firm should prompt its price. We denote this threshold of niche product, neutral product and mainstream product as $R_{0}^{N I}, R_{0}^{N E}$ and $R_{0}^{M}$ respectively. And by comparing them we can get Proposition 8.

Proposition 8: When $1 \leq v \leq 1.499, R_{0}^{N I}>R_{0}^{N E}>R_{0}^{M} ;$ when $1.499<v \leq 2, R_{0}^{N E}>R_{0}^{N I}>R_{0}^{M}$.

The relationship between $R_{0}^{N I}, R_{0}^{N E}$ and $R_{0}^{M}$ can be shown in the Figure 4. Though the average rating is relatively higher the firm has to reduce niche product's price when $1 \leq v \leq 1.499$. And the firm has to reduce neutral product's price though its average rating is relatively higher when $1.499<v \leq 2$. The mainstream product may maintain the same price as first-period price though its average rating is relatively lower. 


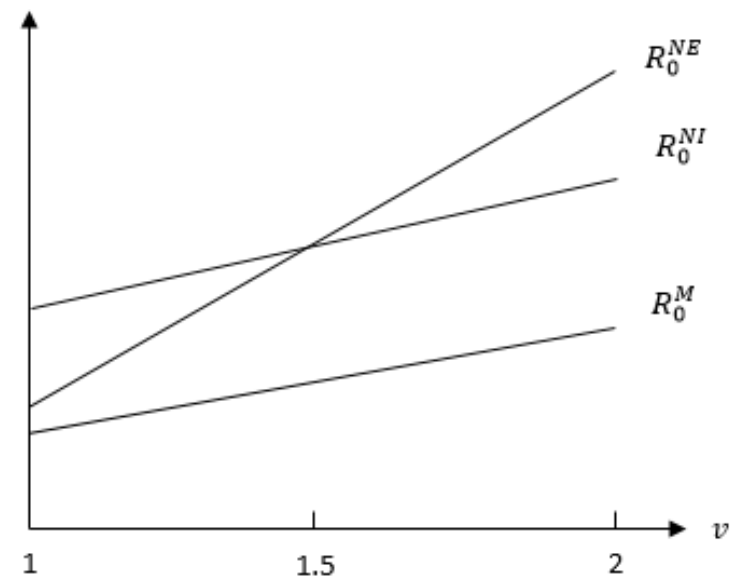

Figure 4: The relationship between $R_{0}^{N I}, R_{0}^{N E}$ and $R_{0}^{M}$

We further investigate the profitability of the consumer reviews by comparing the optimal profits obtained with and without consumer reviews. We denote the expectation of the profit gap as $\Delta \pi$. For niche product, neutral product and mainstream product, we refer to these gaps as $\Delta \pi^{N I}, \Delta \pi^{N E}$ and $\Delta \pi^{M}$, respectively.

$$
\begin{gathered}
\Delta \pi^{N I}=E\left[\pi_{R}^{N I} \mid p_{R, 1}^{N *^{*}}\right]-\frac{8 v^{3}}{27}, \\
\Delta \pi^{N E}=E\left[\pi_{R}^{N E} \mid p_{R, 1}^{N E^{*}}\right]-\frac{v^{2}}{2}, \\
\Delta \pi^{M}=E\left[\pi_{R}^{M} \mid p_{R, 1}^{M^{*}}\right]-\left(\frac{8 v}{9}+\frac{4\left(v^{2}-2 v+4\right)^{\frac{3}{2}}}{27}+\frac{4 v^{2}}{9}-\frac{4 v^{3}}{27}-\frac{32}{27}\right) .
\end{gathered}
$$

Numerical finding: Offering online consumer ratings will benefit the profitability of the firm by increasing the expected total profit. Niche product will enjoy the largest benefit from online consumer ratings while mainstream product enjoys the least, that is $\Delta \pi^{N \prime}>\Delta \pi^{N E}>\Delta \pi^{M}$ for any $v, 1 \leq v \leq 2$.

When there are no online consumer ratings, the estimation of the unobservable value differs greatly from its true value. While online consumer ratings are available, the firm updates to get a more accurate estimation of the unobservable value according to the average consumer rating. For niche products, since the demand will change dramatically with the price, the firm benefits more from accurate information by adjusting selling price in the second period. On the other hand, for mainstream products, the demand will be less sensitive to the price. Thus, the firm has less pricing power to manipulate the market demand and will benefit less from more accurate information.

\section{Discussions and Future Research}

In this section, we conclude our main results and discuss the possible directions for future research.

\subsection{Discussions}

We consider the consumer ratings as the research perspective in this paper, and study how the average consumer ratings form. We take not only the value dimensions of the product but also misfit dimensions into account. So consumer ratings represent the consumers' overall feeling about this shopping experiences and is a measure of shopping satisfaction and have more practical significance. Most existing papers have studied the impact of consumer ratings on the pricing strategies for neutral products. Here we consider the different pricing strategies for mainstream products, neutral products and niche products and draw the following conclusions.

By considering the dynamics of pricing, we show how the firm should use its first-period price to induce proper online rating. With the development of Internet technology, the cost of consumers using the Internet for information exchange is getting lower and lower, and online consumer ratings are also getting more and more attention. It will increase a firm's profit when they consider online consumer ratings into pricing strategies in niche product market, neutral product market or mainstream product market. So firms can take positive steps to guide consumers to rate the product. In addition, as a digital indicator of online consumer ratings, consumer ratings are more intuitive and vivid, conveying the 
overall experience of consumer shopping, improving the accuracy of consumers' understanding of products' unobservable value in the second period and better judging the products' net utility. Firms can also be based on consumer ratings to understand the value of the products, adjust prices, and enjoy greater profits.

The firm should adopt different optimal pricing strategies for the three different types of product (i.e., mainstream, neutral and niche). This perspective has practical implications. For example, for a product with moderate value, the firm should use an ascending (descending) pricing policy across periods, if the product is niche (neutral). When considering consumer ratings, mainstream products increase profit in maximum extent, niche products increase profit in moderate extent, and neutral products increase profit the in minimum extent. So consumer online ratings play different roles on the firm's profitability for different types of products. Mainstream products firms should pay more attention to consumer ratings, for it will bring more profit.

The optimal price set by the firm should be different when considering the consumer rating and not considering it. In niche product markets: when firms provide consumer rating systems and the value of a product is small, the firm should reduce the first-period price to obtain a higher level of consumer rating and then set the second-period price according consumer ratings; when the value of the products is large, the firm can set a higher first-period price and obtain more consumer surplus, and then make the second-period price through consumer rating produced in the first period. It is essential for firms to understand the value of the product correctly, and develop different pricing strategies according to the value of product, because it will enable firms to make greater profits. In the neutral product market: when considering consumer ratings, firms set a lower price in the first period to get a higher rating for consumers and then make the second-period price through consumer rating produced in the first period. In the mainstream product market: when considering consumer ratings, firms set a higher price in the first period to gain more consumer surplus in time and then make the second-period price through consumer rating produced in the first period. It is a key factor for a company to make a price decision by correctly identifying whether the product being sold is a niche product, a neutral product or a mainstream product.

\subsection{Future Research}

In our study, the firms only provide satisfied and not satisfied to consumers to rate the product. It may not be accurate enough for consumer to express the extent of consumers' satisfaction, so in the future research can examine how consumer ratings affect firms' pricing strategies and consumers' purchasing decisions when the consumer ratings is not only the two options.

We do not consider that how consumer ratings influence pricing strategies for themselves and their competitors and how consumers make purchasing decisions when the market environment is competitive. When there are substitutable products on the market, consumers' purchasing decisions will change and firms should make decisions not only considering the purchase behavior of consumers but also considering the influence of competitors' prices.

Our study focuses on durable products, the quality of which cannot be fully described on online websites. Thus, our model is particularly fit to products like the electronic devices, apparel, books, and games. For future research, it would be worthy to explore the pattern of price changes in response to online reviews for different product customization level in other industries like tourism and finance. But the consumers and their utility should be carefully modeled, so that the consumers in the two selling periods may be overlapped and their utility functions should be interdependent.

Our paper is based on analytical modeling. With abundant data of online consumer reviews, it would be interesting to use experimental and empirical methods to study the interplay among pricing, online consumer ratings, and product customization degree.

\section{Acknowledgements}

This work was supported in part by the National Natural Science Foundation of China $(71671067,71301050,71471062$ and 71431004), the Shanghai Pujiang Program (17PJC023, 13PJC022) and the Fundamental Research Funds for the Central Universities. Yifan Wu corresponds for this article.

\section{Websites Lists}

Site 1: Zhongguancun Online http://www.zol.com.cn

Site 2: Amazon

https://www.amazon.com 


\section{References}

[1] N. Amblee and T. Bui, Harnessing the influence of social proof in online shopping: The effect of electronic word of mouth on sales of digital microproducts, International Journal of Electronic Commerce, vol. 16, no. 2, pp. 91$114,2011$.

[2] N. Archak, A. Ghose and P. G. Ipeirotis, Deriving the pricing power of product features by mining consumer reviews, Management Science, vol. 57, no. 8, pp. 1485-1509, 2011.

[3] L. Caruccio, V. Deufemia and G. Polese, Understanding user intent on the web through interaction mining, Journal of Visual Languages \& Computing, vol. 31, pp. 230-236, 2015

[4] L. V. Casaló, C. Flavián, M. Guinalíu, and Y. Ekincic, Avoiding the dark side of positive online consumer reviews: Enhancing reviews' usefulness for high risk-averse travelers, Journal of Business Research, vol. 68, no. 9, pp. 1829-1835, 2015.

[5] R. Cate, Word of mouth on the web: The impact of web 2.0 on consumer purchase decisions, Journal of Advertising Research, vol. 47, no. 4, pp. 436-447, 2007.

[6] R. Chaklader and M. B. Parkinson, Data-driven sizing specification utilizing consumer text review, Journal of Mechanical Design, vol. 139, no. 11, pp. 111406-1-7, 2017.

[7] H. Chang, P. Fang and C. Huang, The impact of online consumer reviews on value perception: The dual-process theory and uncertainty reduction, Journal of Organizational and End User Computing, vol. 27, no. 2, pp. 32-57, 2015.

[8] Y. Chen and J. Xie, Third-party product review and firm marketing strategy, Marketing Science, vol. 24, no. 2, pp. 218-240, 2005.

[9] Y. Chen and J. Xie, Online consumer review: Word-of-mouth as a new element of marketing communication mix, Management Science vol. 54, no. 3, pp. 477-491, 2008.

[10] J. A. Chevalier and D. Mayzlin, The effect of word of mouth on sales: Online book reviews, Journal of Marketing Research, vol. 43, no. 3, pp. 345-354, 2016.

[11] E. K. Clemons, G. G. Gao and L. M. Hitt, When online reviews meet hyper differentiation: A study of the craft beer industry, Journal of Management Information Systems, vol. 23, no. 2, pp. 149-171, 2014.

[12] G. Cui, H. K. Lui and X. Guo, The effect of online consumer reviews on new product sales, International Journal of Electronic Commerce, vol. 17, no. 7, pp. 39-58, 2012.

[13] C. Dellarocas, X. Q. Zhang and N. F. Awad, Exploring the value of online product reviews in forecasting sales: The case of motion pictures, Journal of Interactive Marketing, vol. 21, no. 1, pp. 23-45, 2010.

[14] V. Deufemia, M. Giordano, G. Polese, and L.M. Simonetti, Exploiting interaction features in user intent understanding, in Proceedings of APWEB'13, ser. Lecture Notes in Computer Science, vol. 7808, Springer, Berlin, Heidelberg, 2013, pp. 506-517.

[15] D. Godes and D. Mayzlin, Using online conversations to study word-of-mouth communication, Marketing Science vol. 23, no. 4, pp. 545-560, 2004.

[16] U. Gretzel and K. Hyan, Use and impact of online travel reviews, Information \& Communication Technologies in Tourism, vol. 26, no. 1, pp. 35-46, 2008.

[17] B. Gu, Q. Tang and A. Whinston, The influence of online word-of-mouth on long tail formation, Decision Support Systems, vol. 56, no. 1, pp. 474-481, 2013.

[18] C. Flavián, R. Gurrea and C. Orús, Choice confidence in the webrooming purchase process: The Impact of Online positive reviews and the motivation to touch, Journal of Consumer Behaviour, vol.15, no. 5, pp. 459-476, 2016.

[19] S. H. Ha, S.Y. Bae and L. K. Son, Impact of online consumer reviews on product sales: Quantitative analysis of the source effect, Applied Mathematics \& Information Sciences, vol. 9, no. 2, 373-387, 2015.

[20] Q. C. He and Y. J. Chen, Dynamic pricing of electronic products with consumer reviews, Omega, vol. 80, pp. 123-134, 2018.

[21] N. Hu, N. S. Koh and S. Reddy, Ratings lead you to the product, reviews help you clinch it? The mediating role of online review sentiments on product sales, Decision Support Systems, vol. 57, no. 1, pp. 42-53, 2014.

[22] N. Hu, L. Liu and J. Zhang, Do online reviews affect product sales? The role of reviewer characteristics and temporal effects, Information Technology and Management, vol. 9, no. 3, pp. 201-214, 2008.

[23] V. Ivar and S. Daphne, Tried and tested: The impact of online hotel reviews on consumer consideration, Tourism Management, vol. 30, no. 1, pp. 123-127, 2009.

[24] Y. Jiang and H. Guo, Design of consumer review systems and product pricing, Information Systems Research, vol. 26, no. 4, pp. 714-730, 2015.

[25] A. Kostyk, M. Niculescu and J. M. Leonhardt, Less is more: Online consumer ratings' format affects purchase intentions and processing, Journal of Consumer Behavior, vol. 16, no. 5, pp. 434-441, 2017.

[26] D. Kuksov and Y. Xie, Pricing, frills, and customer ratings, Marketing Science, vol. 29, no. 5, pp. 925-943, 2010.

[27] H. C. Kuo and C. Nakhata, Price promotions and products with low consumer ratings, Journal of Consumer Marketing, vol. 33, no. 7, pp. 517-527, 2016.

[28] Y. Kwark, J. Q. Chen and S. Raghunathan, Online product reviews: Implications for retailers and competing manufacturers, Information Systems Research, vol. 25, no. 1, pp. 93-110, 2014

[29] Y. Kwark, J. Chen and S. Raghunathan, Platform or wholesale? A strategic tool for online retailers to benefit from third-party information, MIS Quarterly, vol.41, no.3, pp. 763-785, 2017.

[30] A. Lawani, M.R. Reed, T. Mark, and Y. Zheng, Reviews and price on online platforms: Evidence from sentiment analysis of airbnb reviews in Boston, Regional Science and Urban Economics, vol. 75, pp. 22-34, 2019. 
[31] J. H. Lee, H. J. Sun and J. H. Park. The role of entropy of review text sentiments on online WOM and movie box office sales, Electronic Commerce Research and Applications, vol. 22, no. 22, pp. 42-52, 2017

[32] Y. Lee and Y. Tan, Effects of different types of free trials and ratings in sampling of consumer software: An empirical study, Journal of Management Information Systems, vol. 30, no. 3, pp. 213-246, 2013.

[33] X. Li and M. Hitt, Self-selection and information role of online product reviews, Information Systems Research, vol. 19, no. 4, pp. 456-474, 2008.

[34] X. Li and L. M. Hitt, Price effects in online product reviews: An analytical model and empirical analysis, MIS Quarterly, vol.34, no.4, pp. 809-831, 2010.

[35] F. Lin, J. Zhang and W. Tang, A joint dynamic pricing and advertising model of perishable products, Journal of the Operational Research Society, vol. 66, no.8, pp. 1341-1351, 2015.

[36] H. Öğüt and B.K. Onur Taş, The influence of internet customer reviews on the online sales and prices in hotel industry, The Service Industries Journal, vol. 32, no. 2, pp. 197-214, 2011.

[37] Y. Papanastasiou and N. Savva, Dynamic pricing in the presence of social learning and strategic consumers, Management Science, vol. 63, no. 4, pp. 919-939, 2017.

[38] X. P. Shi and Z. Q. Liao, Online consumer review and group-buying participation: The mediating effects of consumer beliefs, Telematics and Informatics, vol. 34, no. 5, pp. 605-617, 2017.

[39] M. Sun, How does the variance of product ratings matter, Management Science, vol. 58, no.4, pp. 696-707, 2012.

[40] X. M. Su, Intertemporal pricing with strategic customer behavior, Management Science, vol. 53, no. 5, pp. 726741,2007

[41] D. Tevfik and L. Maarten, Niche marketing revisited: Concept, applications and some European cases, European Journal of Marketing, vol. 28, no. 4, pp. 39-55,1994.

[42] B. Wang, A comparison of consumer reviews on the sales of experience and search goods, International Journal of Services and Standards, vol. 8, no. 4, pp. 332-346, 2013.

[43] H. Wang, W. Zhang and L. Zheng, Dynamic pricing in B2C based on online product reviews, Procedia Engineering, vol. 23, no. 23, pp. 270-275, 2011.

[44] M. Yu, L. Debo and R. Kapuscinski, Strategic waiting for consumer-generated quality information: Dynamic pricing of new experience goods, Management Science, vol. 62, no. 2, pp. 410-435,2016.

[45] F. Zhu and X. Zhang, Impact of online consumer reviews on sales: The moderating role of product and consumer characteristics, Journal of Marketing, vol.2, no. 74, pp. 133-148, 2010. 